\title{
Enhanced spring convective barrier for monsoons in a warmer world?
}

\author{
A letter
}

\author{
Anji Seth • Sara A. Rauscher • Maisa Rojas • \\ Alessandra Giannini • Suzana J. Camargo
}

Received: 16 June 2010 / Accepted: 14 October 2010 / Published online: 10 November 2010

(C) Springer Science+Business Media B.V. 2010

\begin{abstract}
Twenty-first century climate model projections show an amplification of the annual cycle in tropical precipitation with increased strength in both wet and dry seasons, but uncertainty is large and few studies have examined transition seasons. Here we analyze coupled climate model projections of global land monsoons and show a redistribution of precipitation from spring to summer in northern (North America, West Africa and Southeast Asia) and southern (South America, Southern Africa) regions. The annual cycle changes are global in scale. Two mechanisms, remote (based on tropospheric stability) and local (based on low level and surface moisture), are evaluated through the annual cycle. Increases in tropospheric stability persist from winter into spring and are reinforced by a reduction in surface moisture conditions, suggesting that in spring both remote and local mechanisms act to inhibit convection. This enhanced spring convective barrier leads to reduced early season rainfall; however, once sufficient increases in moisture (by transport) are achieved, decreases in tropospheric stability result in increased precipitation during the late rainy season. Further examination of this mechanism is needed in observations and models, as the projected changes would have substantial implications for agriculture, water management, and disaster preparedness.
\end{abstract}

\footnotetext{
A. Seth $(\varangle)$

University of Connecticut, Storrs, CT, USA

e-mail: anji.seth@uconn.edu
}

\section{S. A. Rauscher}

Los Alamos National Laboratory, Los Alamos, NM, USA

M. Rojas

University of Chile, Santiago, Chile

A. Giannini

International Research Institute for Climate and Society, Palisades, NY, USA

\section{S. J. Camargo}

Lamont Doherty Earth Observatory, Palisades, NY, USA 


\section{Introduction}

In this article we study 21st century projections of the annual cycle of precipitation in global land monsoon regions (e.g. Wang and Ding 2006). Seasonally wet/dry monsoons result from directional shifts in winds and moisture transport due to the longer response time of oceans versus land to the annual cycle of solar heating (Chao and Chen 2001; Webster et al. 1998). Under anthropogenic warming scenarios, land-sea thermal contrasts are expected to increase in part due to differences in thermal inertia between land and ocean, but largely because oceans divert more of the anomalous incoming energy into latent heat rather than increasing surface temperature (Sutton et al. 2007). Where moisture is abundant (i.e., over oceans) warmer surface temperatures lead to increased evaporation due to the nonlinear Clausius-Clapeyron relationship, and robust increases in atmospheric water vapor, which are associated with weakening of the tropical (Hadley, Walker and monsoon) circulations (Held and Soden 2006). Despite this weakening of tropical circulations, multi-model climate projections indicate a tendency towards increased monsoon precipitation due to increased low-level moisture convergence (Christensen et al. 2007). Evidence for future precipitation increases has been documented for Australia (Meehl et al. 2007a) and South Asia (Douville et al. 2000), where a 5-25\% increase in precipitation was found in the models that best represent the interannual variability and teleconnections associated with the monsoon (Annamalai et al. 2007). However, the North American monsoon region is expected to become drier in the annual mean (Seager et al. 2007), and much uncertainty exists for the future of the West African monsoon and tropical South America (e.g. Giannini et al. 2008; Vera et al. 2006). The response of global monsoons to greenhouse warming is complicated by a number of factors, including the expected dynamical weakening of the tropical circulation (Tanaka et al. 2005; Vecchi and Soden 2007), related changes in the tropical tropospheric stability (Chou et al. 2001; Neelin et al. 2003), and the regional effects of aerosols and black carbon (Lau et al. 2006; Meehl et al. 2008).

The monsoon response to greenhouse gas forcing has been examined using a framework based on moist static energy $(M S E)$, which exploits the role of evaporation in both energy and water budgets (Neelin and Held 1987). Neelin and collaborators (Neelin et al. 2003; Chou and Neelin 2004; Chou et al. 2009) use the $M S E$ framework to evaluate changes in horizontal gradients in humidity, whereby core regions of tropical deep convection demonstrate increases in lowlevel moisture and moisture convergence, leading to decreased gross moist stability, and are thus projected to become wetter in a warmer world ("rich get richer"). The margins of deep convecting regions, which do not have access to the same levels of increased low-level moisture due to advection from nearby nonconvecting regions, show decreased precipitation ("upped ante"). Giannini (2010) has used this $M S E$ framework to explore two competing mechanisms involved in the divergent responses of climate models to greenhouse gas forcing in the Sahel region: remote (or top down) and local (or bottom up). First, in the remote mechanism, large scale tropospheric warming controls vertical stability in the global tropics (Sobel et al. 2002; Chiang and Sobel 2002), and reduces continental precipitation in those regions that cannot meet the increasing demand for near-surface moist static energy (Chou et al. 2001; Neelin et al. 2003). In this case, the precipitation reduction is reinforced by a consequent reduction in evaporation due to decreased precipitation recycling. 
In the second, local mechanism, the land surface response to anthropogenically enhanced terrestrial radiative forcing dominates. Where surface moisture is sufficient, increased evaporation leads to near-surface increases in moist static energy, instability, and precipitation. The increase in precipitation is then reinforced by enhanced moisture convergence. Where moisture is insufficient, increased terrestrial radiation is balanced by increased sensible heat flux. In the models that project drying in the Sahel, the remote mechanism dominates, while in models projecting a wetter Sahel the local mechanism is at work (Giannini 2010).

These studies have focused on the fully established wet and dry seasons (DecFeb, Jun-Aug). However, studies that examine the complete annual cycle indicate a redistribution of precipitation within the annual cycle. For example, the South American and West African monsoons both exhibit drying in spring and increased precipitation during summer in projections (Seth et al. 2010; Biasutti and Sobel 2009; Biasutti et al. 2009).

In the present analysis, we examine global land monsoon regions using the $M S E$ framework as described by Giannini (2010), which acknowledges the potential importance of the surface energy budget in understanding precipitation in land monsoon regions. The analysis is performed through the annual cycle, thus permitting a view of the transition seasons. We will show that, despite model uncertainties in annual precipitation, a shift in the annual cycle is discernable and appears to be part of a global response to greenhouse forcing. We argue that the transition from dry to wet season is likely to be important in order to understand changes in the monsoon regions.

\section{Spring drying in continental monsoons}

Despite the disagreement among climate models regarding projections of annual or seasonal mean Sahel precipitation in the 21st century (e.g. Giannini et al. 2008), there is consensus regarding a weakening of early and strengthening of late season rainfall (Biasutti and Sobel 2009). Models indicate a similar reduction in spring and an increase in summer precipitation in the core region of the South American monsoon, which is associated with insufficient low level moisture convergence in spring and a substantial increase in convergence during summer (Seth et al. 2010). Multi-model projected changes in the annual cycles of precipitation, shown averaged over longitude for each monsoon region in Fig. 1 (c-i, see Section 4 for region definitions), demonstrate drying during spring, Mar-May at $15-25^{\circ} \mathrm{N}$ (Sep-Nov at $10-20^{\circ} \mathrm{S}$ ) in the northern (southern) hemisphere. In addition to South America and West Africa, a shift from spring to summer precipitation is present in North America, Southern Africa, and Southeast Asia. Only South Asia and Australia exhibit mixed results during spring. The shift is visible in averages of the four northern and three southern monsoon regions (Fig. 1a and b).

A robust large-scale response to greenhouse gas forcing has been shown in tropical precipitation wherein summer hemisphere monsoons and winter hemisphere dry seasons are simultaneously strengthened, creating an asymmetric inter-hemispheric signal (Tan et al. 2008). The shift in the annual cycle of precipitation in the monsoon regions (Fig. 1) appears to be part of this global response. The reduction of spring and increase in summer can be seen in the global annual cycle of precipitation averaged 

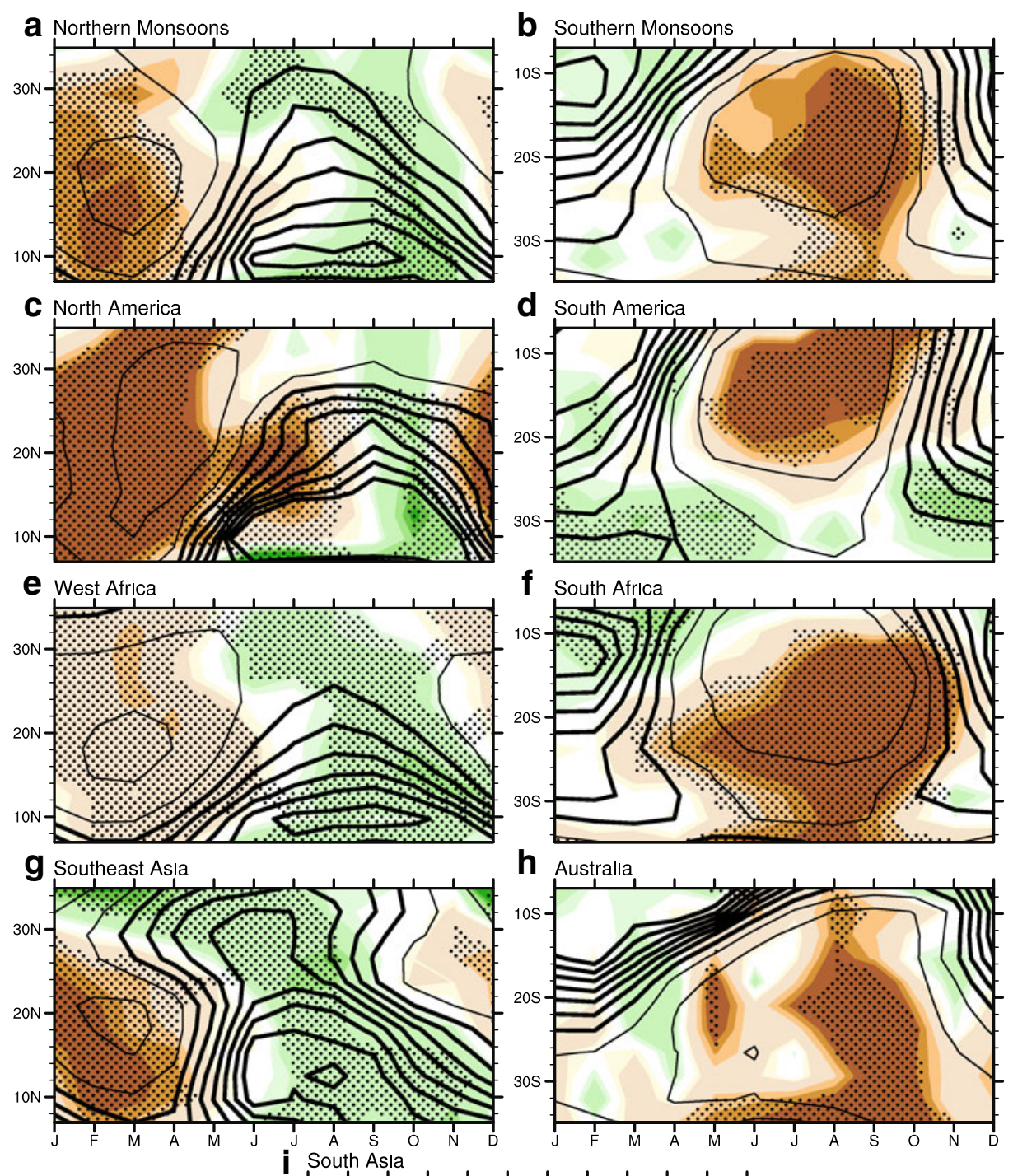

h Australia
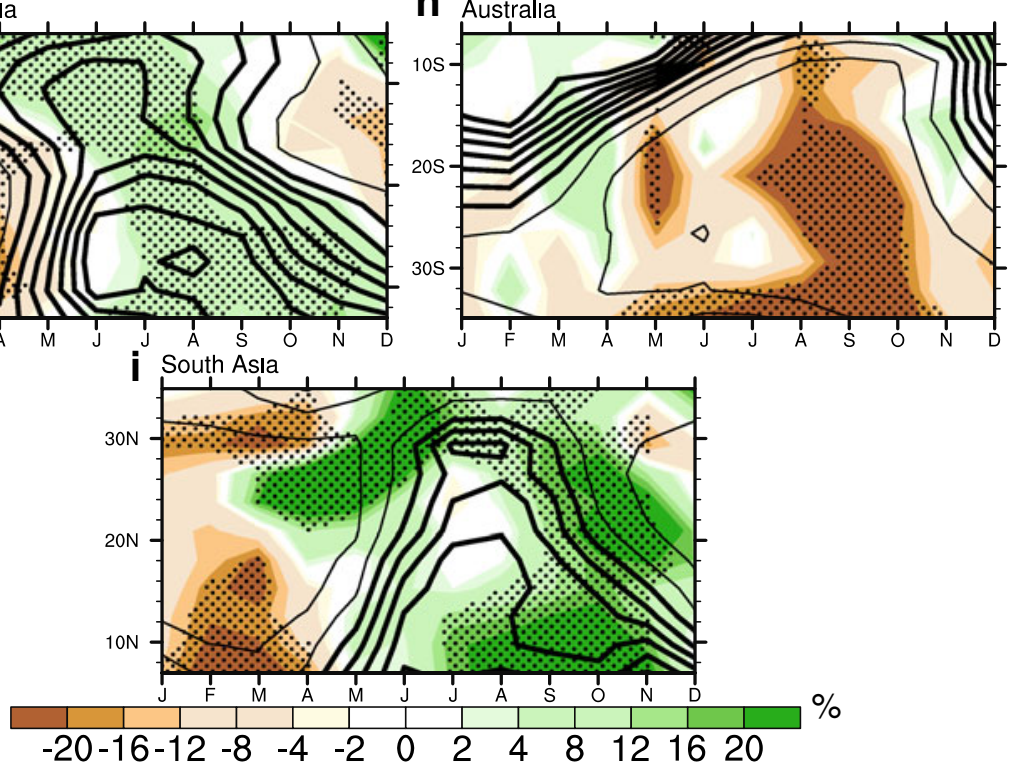
Fig. 1 Multi-model average precipitation \% differences (colors) for periods 2070-2099 (A2) minus 1970-1999 (20C) averaged over longitude for the monsoon regions, shown month versus latitude. Black contours represent climatological precipitation for each region (interval $1 \mathrm{~mm} / \mathrm{day}$, from 1-12, with heavy lines for precipitation greater than $2 \mathrm{~mm} /$ day). Areas of significant change are stippled

over longitude (Fig. 2a). The precipitation reduction is stronger and extends deeper into the rainy season over land (Fig. 2b), while the late rainy seasons (Feb-Mar, Aug-Oct) show clear strengthening of summer hemisphere rainfall.

Can this global-scale shift in the timing of tropical precipitation be understood in terms of the remote and local mechanisms outlined above? Recall the remote mechanism is related to increased stability that results from a warmer tropical troposphere. Gross stability of the tropical tropospheric is the difference between $M S E$ in the poleward flow at upper levels and the low-level equatorward flow (Held 2001). The moist static energy includes the effects of temperature and moisture and is defined $M S E=D S E+L q$, where the dry static energy is defined $D S E=$ $c_{p} T+g Z$, and $c_{p}$ is the specific heat at constant pressure, $T$ is the layer temperature, $g$ is gravity, $Z$ is geopotential height, $L$ is the latent heat of evaporation, and $q$ is specific humidity. Because there is little water vapor in the flow aloft, the MSE in
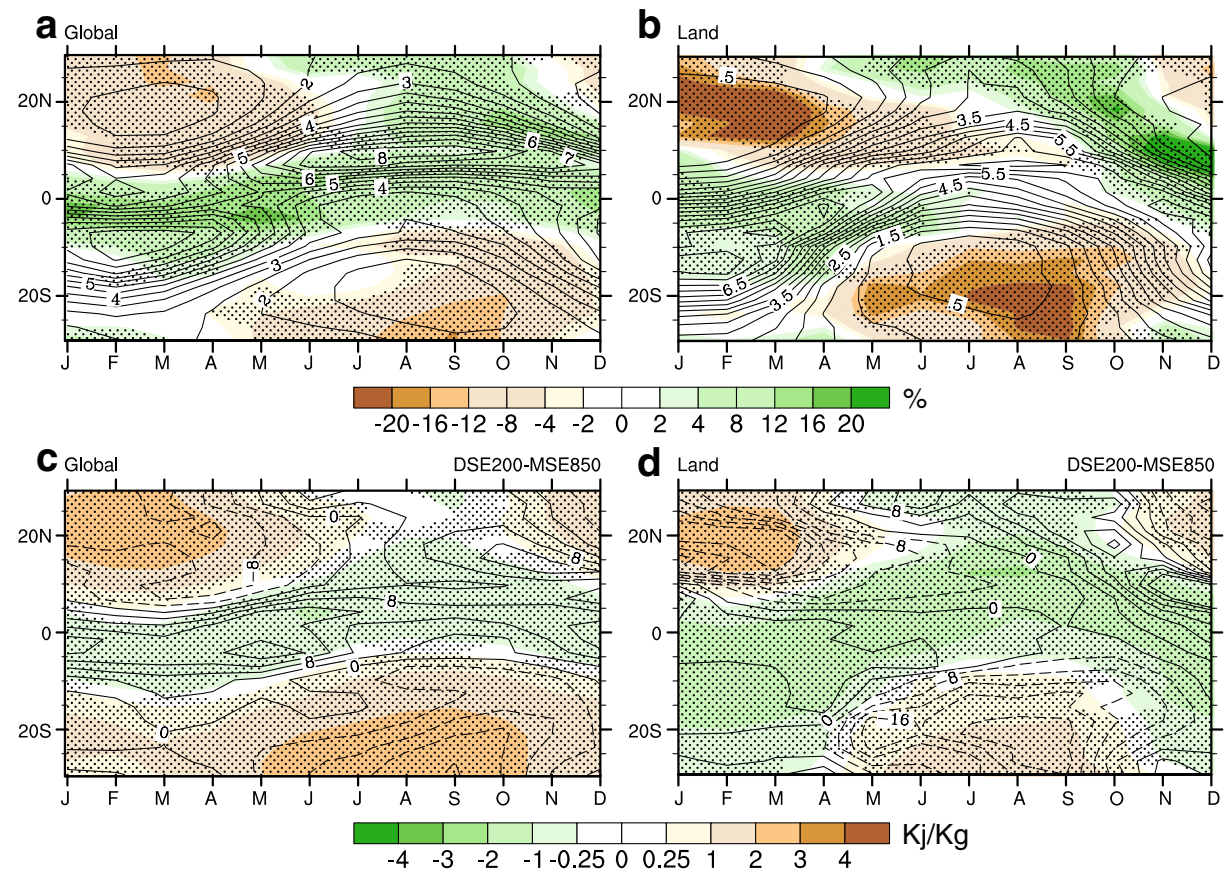

Fig. 2 Multi-model differences for periods 2070-2099 (A2) minus 1970-1999 (20C) averaged over longitude globally (left) and for land only (right), shown month versus latitude for \% precipitation (colors) and precipitation climatology for period 1970-1999 (black contours, interval $1 \mathrm{~mm} / \mathrm{day}$, from 1-12) (a, b), and vertical gradient of moist static energy (200-850 hPa MSE, Kj/Kg), where positive differences indicate increased tropospheric stability (brown) and with black contours showing \% precipitation changes $(\mathbf{c}, \mathbf{d})$. Areas of significant change are stippled 
the upper troposphere is equivalent to $D S E$ (e.g. Held 2001). Thus, as a measure of free tropospheric stability, we examine changes in the vertical gradient of moist static energy, $v M S E$, which is defined $v M S E=D S E_{200}-M S E_{850}$.

Figure $2 \mathrm{c}$ and $\mathrm{d}$ present the annual cycle of $v M S E$ averaged over longitude globally (c) and for land only (d), where positive (negative) changes in vMSE indicate greater stability (instability), which would tend to inhibit (enhance) precipitation in future scenarios. Precipitation \% differences are also shown in Fig. 2c and d as black contours. Despite increases in surface temperatures and humidity, changes in tropospheric stability are not consistent throughout the year in the subtropics. In winter, the $v M S E$ increases, indicating greater stability to convection, and in summer it becomes more negative (less stable), as expected from previous results. Figure $2 \mathrm{~d}$ also shows that during the spring transition to the wet season (Aug-Oct and Mar-May), the positive $v M S E$ changes from the dry season persist, indicating increased stability to convection over land. This result suggests that springtime drying is controlled at least in part by the remote (top down) mechanism.

If we examine Fig. 2d closely, the precipitation reductions continue into Nov ( $\mathrm{SH})$ and Jun (NH), even after $v M S E$ indicates a switch from a more stable to less stable troposphere. In order to explore this extension of the drying into early summer, we examine (Fig. 3) the terms which comprise $v M S E$, which include the temperature terms, or $D S E$ at $200 \mathrm{hPa}$, and at $850 \mathrm{hPa}$ the $M S E$ and its components ( $D S E$ and the moisture term, $L q$ ). The reversal of color scales (Fig. 3) between upper (a and b) and lower ( $\mathrm{c}-\mathrm{h})$ levels is designed to visualize that positive changes in $D S E$ at upper levels act to stabilize while positive changes in the $M S E$ terms at lower levels act to destabilize the troposphere. This will also aid in understanding why globally, free tropospheric stability increases much of the year in the subtropics (Fig. 2c).

At upper levels, $D S E_{200}$ increases year-round in the tropics and subtropics, with the largest increases between $20^{\circ} \mathrm{N}-20^{\circ} \mathrm{S}$ which are relatively constant through the year as shown in Fig. 3a and b. Note that statistical significance has been omitted from Fig. 3 for clarity, but is similar to that seen in Fig. 2c and d. Lower level $M S E_{850}$ also increases everywhere, but shows seasonality with the largest increases migrating poleward into the summer hemisphere (Fig. 3c and d). Thus the increased free tropospheric stability during winter and early spring results from a larger increase in $D S E_{200}$ than in $M S E_{850}$, consistent with the remote mechanism. However, this still does not explain the continued reduction in precipitation after tropospheric stability decreases (Fig. 2d, Nov in SH and Jun in NH) and $M S E_{850}$ has increased to warm season values. We further decompose $M S E_{850}$ into its moisture term $L q$ (Fig. $3 \mathrm{e}$ and f) and temperature terms (DSE) (Fig. $3 \mathrm{~g}$ and $\mathrm{h}$ ). The tropics and summer hemisphere rainy seasons are dominated by the moisture term, while the subtropics and dry seasons are controlled by the temperature terms. During the spring transition, increases in $D S E$ continue to be larger than $L q$, which suggests that tropospheric destabilization initially results from increased temperatures. However, until sufficient moisture is imported, decreased stability cannot produce increased precipitation. Is this the local mechanism at work?

Previous work suggests there are three primary phases in the transition from the dry to the wet season in monsoon regions: a local build-up of available potential energy due to increasing latent heat fluxes (initiation), the transition of the large scale circulation which leads to net moisture convergence in the region (development), and once onset is established (mature) an upper-tropospheric anticyclonic circulation 

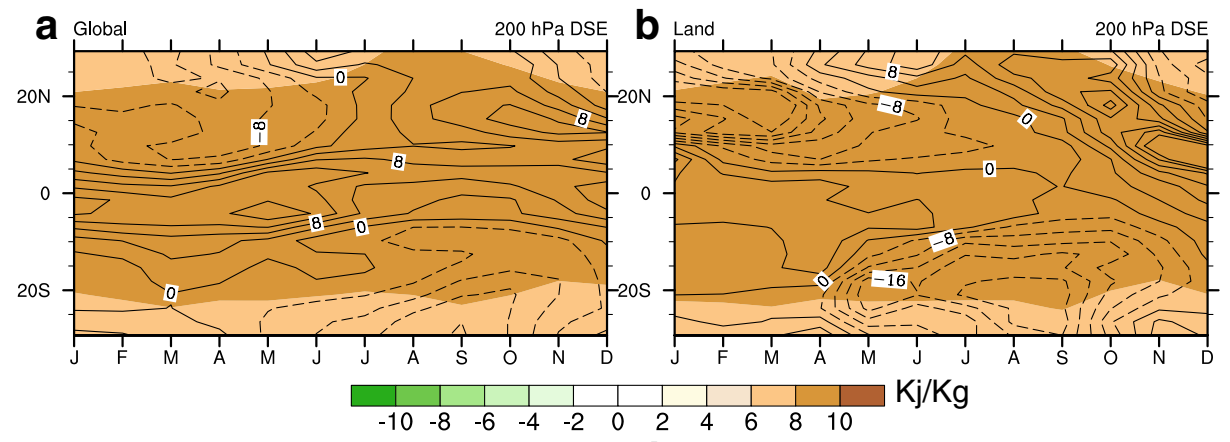

$\mathrm{Kj} / \mathrm{Kg}$
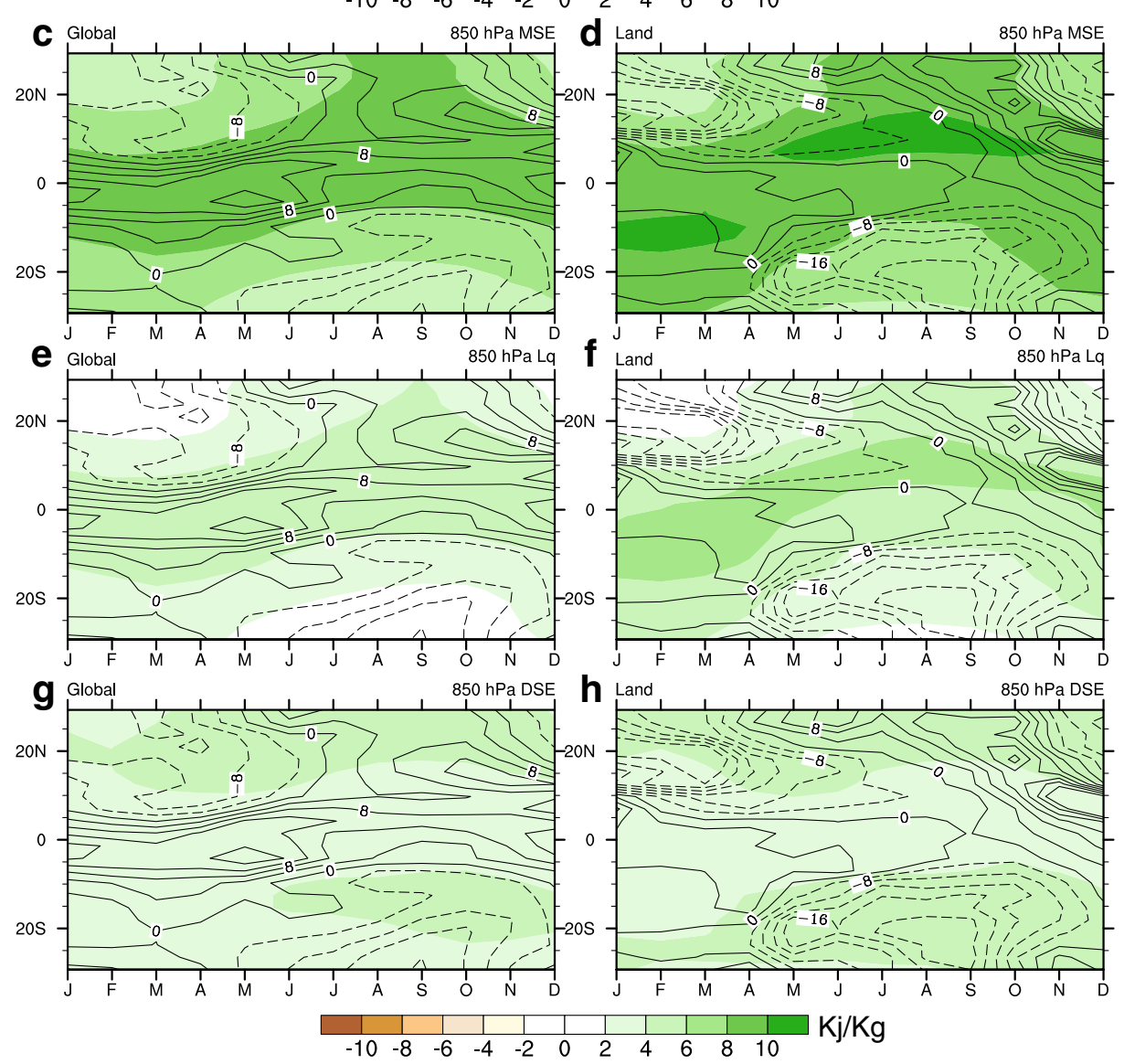

Fig. 3 Multi-model differences for $A 2$ minus $20 C$ averaged over longitude globally (left) and for land only (right), shown month versus latitude for $200 \mathrm{hPa}$ DSE, where positive differences indicate increased stability (brown) (a, b), $850 \mathrm{hPa} \operatorname{MSE}(\mathbf{c}, \mathbf{d}), 850 \mathrm{hPa} \mathrm{Lq}$, moisture term only (e, f) and $850 \mathrm{hPa}$ DSE, temperature terms only $(\mathbf{g}, \mathbf{h})$ in $\mathrm{Kj} / \mathrm{Kg}$, where positive differences indicate decreased stability (green). Black contours represent \% precipitation changes 
continues to spin up until it reaches its full strength ( $\mathrm{Li}$ and $\mathrm{Fu} 2004$ ). The initiation phase is thus sensitive to local latent heat fluxes that have the potential to delay the timing of the large-scale transition. Further, springtime soil moisture anomalies are known to result in a positive feedback to early season precipitation (Collini et al. 2008). The local land surface influence becomes less important once convection has been initiated ( $\mathrm{Li}$ and $\mathrm{Fu} 2004$ ), although land wetness anomalies can also influence rainfall within the monsoon season (Taylor et al. 2010; Grimm et al. 2007).

In the present case, anomalous terrestrial radiation affects the surface energy balance, and as previously mentioned, over oceans and moist land this excess energy
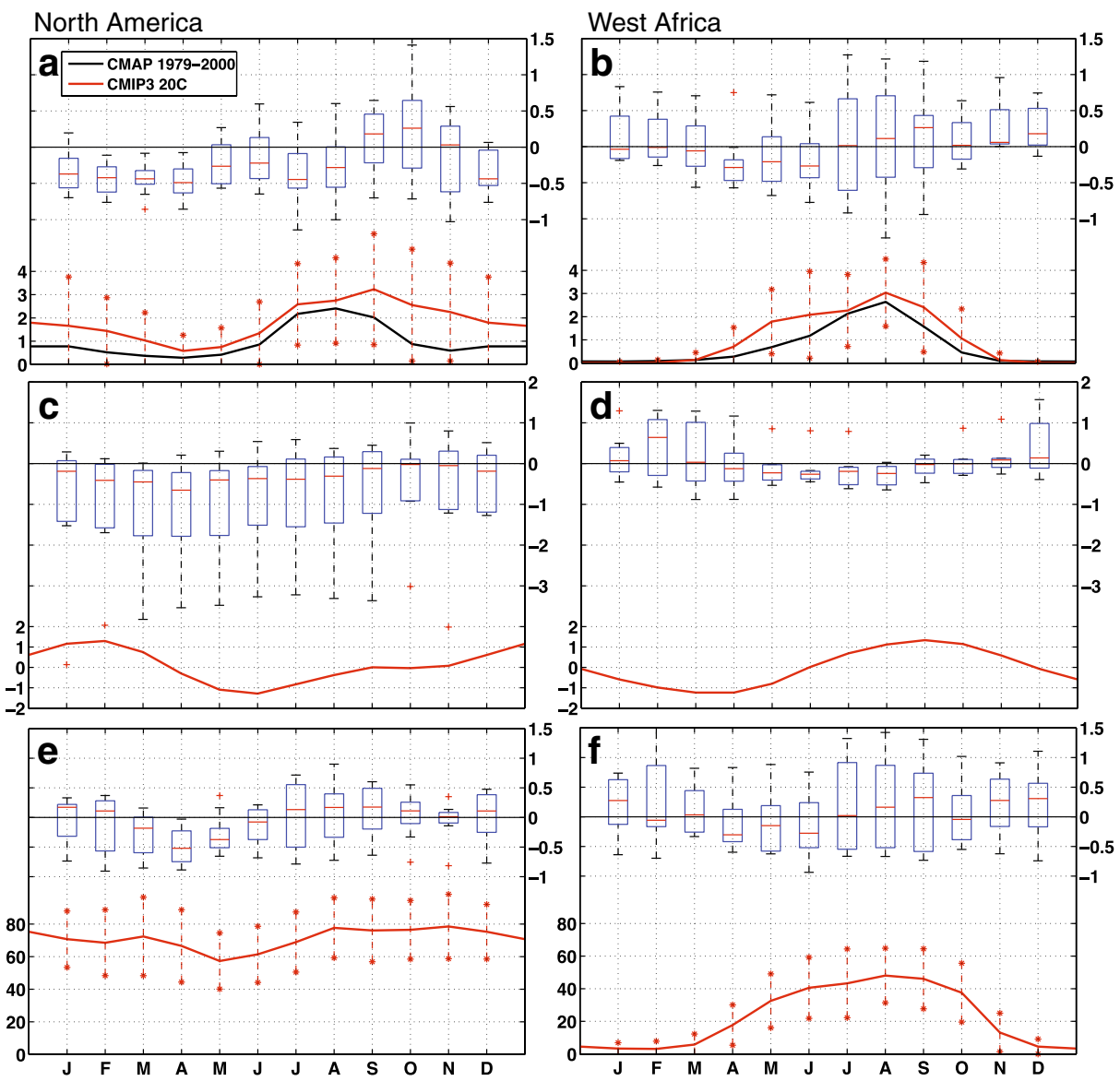

Fig. 4 North America (left) and West Africa (right) monthly climatological observed estimate (black) and model mean (red) precipitation (mm/day) for $20 \mathrm{C}$ where asterisks represent the maximum standard deviation from the multi-model ensemble, and with $A 2-20 C$ differences presented as box plots $(\mathbf{a}, \mathbf{b})$. Same for soil moisture except that climatology has been standardized $(\mathbf{c}, \mathbf{d})$ and latent heat flux $\left(\mathrm{W} / \mathrm{m}^{2}\right)(\mathbf{e}, \mathbf{f})$. Differences are standardized by the monthly standard deviation for $20 \mathrm{C}$ for each model. Upper and lower bounds of boxes represent 75 th and 25 th percentiles, respectively, with whiskers corresponding to \pm 1.5 times the inter-quartile range and outliers shown as red crosses 
is expended in the form of latent heat flux. In subtropical land monsoon regions, where the dry (winter) season is expected to become drier, one might expect a consequent reduction in locally available surface moisture during spring. Therefore, we evaluate the simulated annual cycles of soil moisture and latent heat flux (LHF) as measures of the local mechanism in the projected precipitation changes for the American and African monsoon regions, which display the strongest spring/summer precipitation changes. On this monthly time scale in the four regions (Figs. 4 and 5), LHF (e and f) increases tend to be concurrent with precipitation ( $a$ and $b$ ) in the climatological annual cycle, while soil moisture (c and d) slightly lags the precipitation increases. In the projections, LHF deficits occur during the dry season and do not show positive values until precipitation increases. The LHF increases appear to be coincident with precipitation, and the drier surface conditions in winter persist into the spring. This suggests that the local mechanism, which requires sufficient local moisture, is unable to activate in these monsoon regions until moisture is supplied by atmospheric transport.
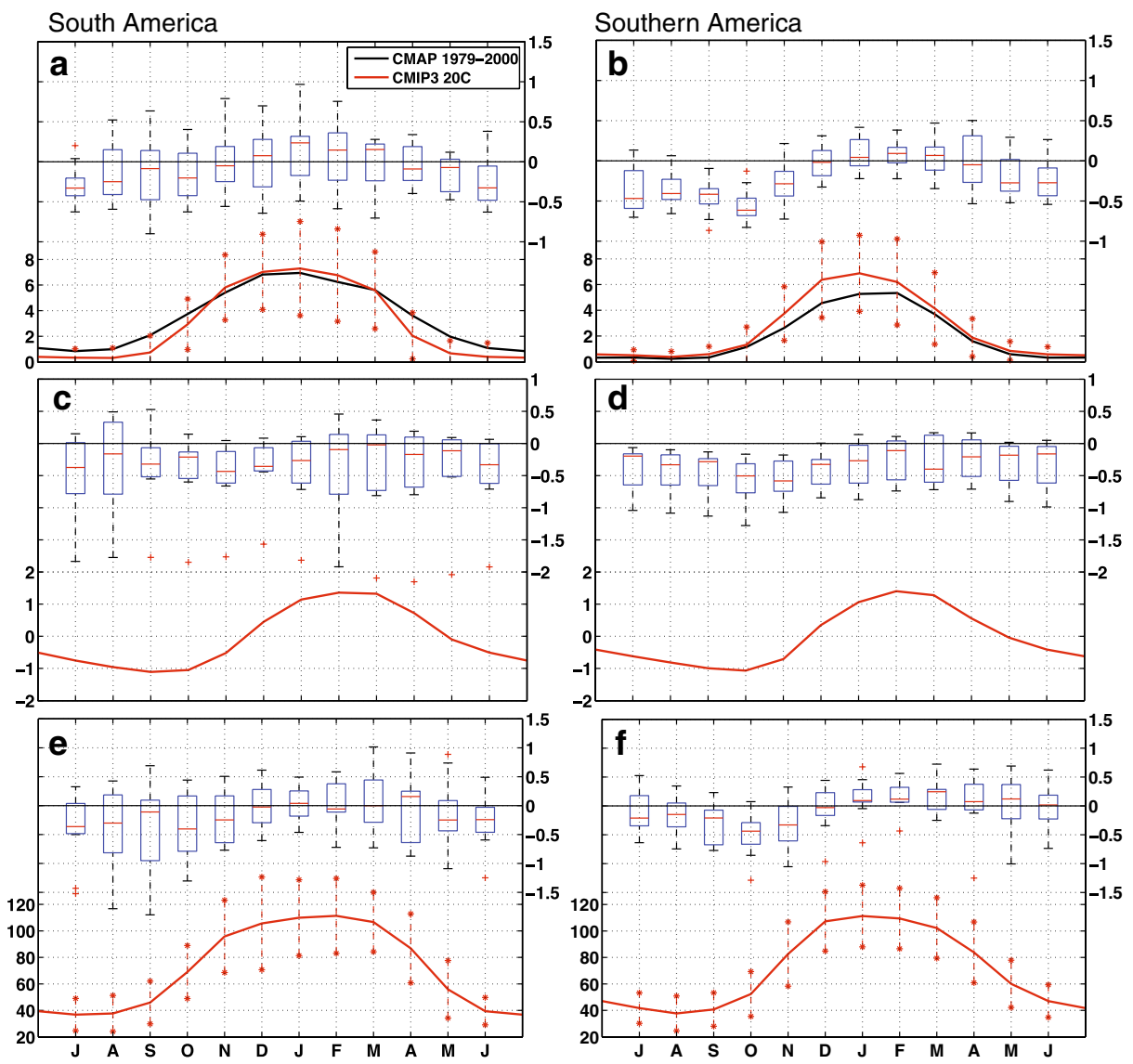

Fig. 5 Same as Fig 4, but for South America and Southern Africa 


\section{Discussion}

While projected total precipitation changes in monsoon regions are uncertain, the results presented here indicate reductions in spring and increases in summer precipitation in multi-model ensemble 21st century climate projections. Competing mechanisms which have been previously identified as being important in precipitation changes, local (enhanced evaporation, decreased stability, and increased precipitation) and remote (warmer troposphere, increased stability, and decreased precipitation) are evaluated in time through the annual cycle, with an emphasis on the transition from dry to wet seasons. The remote (top down) mechanism controls the projected changes during winter and the local (bottom up) mechanism controls during summer. However, during spring, both appear to inhibit convection.

It is well established that the dry season in subtropical regions is enhanced due to increased moisture divergence associated with the descending branch of the Hadley circulation (Meehl et al. 2007a). The measure of tropospheric stability (remote mechanism) presented here shows wintertime increases in stability in the subtropics that are strongest over land. We also find that the increased stability persists into spring and can explain much of the projected precipitation reductions. Even after tropospheric stability decreases, precipitation reductions continue for a short period. Analysis suggests that surface moisture, which is essential for the local mechanism to engage, is lacking at the end of a warmer and drier dry season. Thus both remote and local mechanisms act to create an "enhanced spring convective barrier" leading to reduced early season rainfall; however, once sufficient moisture is imported, decreases in tropospheric stability result in precipitation increases.

Our results suggest that the spring transition may be important in characterizing precipitation changes in monsoon regions, and perhaps in other subtropical regions (e.g., Meso-America) which also show a delayed onset of the rainy season (Rauscher et al. 2008). It must be noted that these model results do not apply to the South Asian or Australian monsoon regions, which may be influenced by additional factors. The South Asian region, for example, has shown increases in pre-season rainfall associated with absorbing aerosols and black carbon (Lau et al. 2006; Meehl et al. 2008). The mechanisms presented here will require further testing with daily data from both observations and improved, higher-resolution climate models to determine if the seasonal changes are due to timing (onset) or character (intensity) of rainfall. In particular, while there is some observed evidence of a weakening of global land monsoon rainfall over the past 50 years (Wang and Ding 2006; Zhou et al. 2008), the weakening is due mostly to Africa and South Asia. Precipitation trends show substantial decadal variability and robust changes in the annual cycle have not been established for most regions (Christensen et al. 2007). A reduction of spring and increase in summer rainfall would have substantial implications for agriculture, water management, and disaster preparedness in monsoon regions.

\section{Methods}

Simulations from ten Coupled Model Intercomparison Project (CMIP3) global climate models (Meehl et al. 2007b) are analyzed with emphasis on the following continental monsoon regions: North America (NAM, 115-102.5W, 20-35N), South 
America (SAM, 60-40W, 10-25S), West Africa (WAf, 10W-20E, 10-25N), South Africa (SAf, 20-40E, 10-25S), South Asia (SAsia, 65-85E, 10-25N), Southeast Asia (SEA, 100-120E, 10-25N), and Australia (Aus, 120-140E, 10-25S). Monthly data from the 20th century historical simulations (20C, for the period 1970-1999) and 21st century SRES A2 (A2, 2070-2099) emissions scenarios are examined.

The 20th Century (20C) simulated precipitation is evaluated using the monthly Climate Prediction Center Merged Analysis of Precipitation (CMAP) (Xie and Arkin 1996). Statistical significance is computed for the difference between the means using a Student's t-test and stippled regions in figures show regions of significance above the $90 \%$ confidence level.

Acknowledgements The authors appreciate critiques from two anonymous reviewers that have improved the quality and presentation of this work, and thank Dr. Fred Kucharski for helpful discussions. The international modeling groups provided data for this analysis, the Program for Climate Model Diagnosis and Intercomparison (PCMDI) for collected and archived the model data, the JSC/CLIVAR Working Group on Coupled Modelling (WGCM) and their Coupled Model Intercomparison Project (CMIP3) and Climate Simulation Panel for organized the model data analysis activity, and the IPCC WG1 TSU for technical support. The IPCC Data Archive at Lawrence Livermore National Laboratory is supported by the Office of Science, U.S. Department of Energy. SR acknowledges the support of the U.S. Department of Energy through the LANL/LDRD Program. This paper is LANL publication LA-UR 09-04807.

\section{References}

Annamalai H, Hamilton K, Sperber KR (2007) The South Asian summer monsoon and its relationship with ENSO in the IPCC AR4 simulations. J Climate 20(6):1071-1092. doi:10.1175/ JCLI4035.1

Biasutti M, Sobel AH (2009) Delayed Sahel rainfall and global seasonal cycle in a warmer climate. Geophys Res Lett 36. doi:10.1029/2009GL041303

Biasutti M, Sobel AH, Camargo SJ (2009) The role of the Sahara low in summertime Sahel rainfall variability and change in the CMIP3 models. J Climate 22(21):5755-5771

Chao WC, Chen B (2001) The origin of monsoons. J Atmos Sci 58(22):3497-3507

Chiang JC, Sobel AH (2002) Tropical tropospheric temperature variations caused by ENSO and their influence on the remote tropical climate. J Climate 15:2616-2631

Chou C, Neelin JD (2004) Mechanisms of global warming impacts on regional tropical precipitation. J Climate 17:2688-2701

Chou C, Neelin JD, Su H (2001) Ocean-atmosphere-land feedbacks in an idealized monsoon. Q J R Meteorol Soc 127:1869-1891

Chou C, Neelin JD, Chen CA, Tu JY (2009) Evaluating the rich-get-richer mechanism in tropical precipitation change under global warming. J Climate 22:1982-2005

Christensen JH, Hewitson B, Busuioc A, Chen A, Gao X, Held I, Jones R, Kolli RK, Kwon WT, Laprise R, Rueda VM, Mearns L, Menéndez CG, Räisänen J, Rinke A, Sarr A, Whetton P (2007) Regional climate projections. In: Solomon S, Qin D, Manning M, Chen Z, Marquis M, Averyt K, Tignor M, Miller H (eds) Climate change 2007: the physical science basis. Contribution of working group I to the fourth assessment report of the Intergovernmental Panel on Climate Change, Chapter 11. Cambridge University Press, New York, pp 235-336

Collini EA, Berbery EH, Barros VR, Pyle ME (2008) How does soil moisture influence the early stages of the South American monsoon? J Climate 21(2):195-213

Douville H, Royer JF, Polcher J, Cox P, Gedney N, Stephenson DB, Valdes PJ (2000) Impact of CO2 doubling on the Asian summer monsoon: robust versus model-dependent responses. J Meteorol Soc Jpn 78:421-439

Giannini A (2010) Mechanisms of climate change in the semiarid African Sahel: the local view. J Climate 23(3):743-756

Giannini A, Biasutti M, Held I, Sobel A (2008) A global perspective on African climate. Clim Change 90(4):359-383. doi:10.1007/s10584-008-9396-y 
Grimm AM, Pal JS, Giorgi F (2007) Connection between spring conditions and peak summer monsoon rainfall in South America: role of soil moisture, surface temperature, and topography in eastern Brazil. J Climate 20(24):5929-5945. doi:10.1175/2007JCLI1684.1

Held IM (2001) The partitioning of the poleward energy transport between the tropical ocean and atmosphere. J Atmos Sci 58:943-948

Held IM, Soden BJ (2006) Robust responses of the hydrological cycle to global warming. J Climate 19:5686-5699

Lau K, Kim M, Kim K (2006) Asian summer monsoon anomalies induced by aerosol direct forcing: the role of the Tibetan Plateau. Clim Dyn 26(7):855-864. doi:10.1007/s00382-006-0114-Z

Li W, Fu R (2004) Transition of the large-scale atmospheric and land surface conditions from the dry to the wet season over Amazonia as diagnosed by the ECMWF re-analysis. J Climate 17(13):2637-2651

Meehl G, Stocker T, Collins W, Friedlingstein P, Gaye A, Gregory JM, Kitoh A, Knutti R, Murphy JM, Noda A, Raper SCB, Watterson IG, Weaver AJ, Zhao ZC (2007a) Climate change 2007: the physical science basis. Contribution of working group I to the fourth assessment report of the Intergovernmental Panel on Climate Change. Chapter: Global climate projections. Cambridge University Press, Cambridge

Meehl GA, Covey C, Delworth T, Mojib L, McAvaney B, Mitchell JFB, Stouffer RJ, Taylor KE (2007b) The WCRP CMIP3 multimodel dataset: a new era in climate change research. Bull Am Meteorol Soc 88:1383-1394

Meehl GA, Arblaster JM, Collins WD (2008) Effects of black carbon aerosols on the Indian monsoon. J Climate 21(12):2869-2882. doi:10.1175/2007JCLI1777.1

Neelin JD, Held IM (1987) Modeling tropical convergence based on the moist static energy budget. Mon Weather Rev 115:3-12

Neelin JD, Chou C, Su H (2003) Tropical drought regions in global warming and El Niño teleconnections. Geophys Res Lett 30. doi:10.1029/2003GL018625

Rauscher SA, Giorgi F, Diffenbaugh NS, Seth A (2008) Extension and intesification of the MesoAmerican mid-summer drought in the twenty-first century. Climate Dynamics 31:551-571. doi:10.1007/s00382-007-0359-1

Seager R, Ting M, Held I, Kushnir Y, Lu J, Vecchi G, Huang HP, Harnik N, Leetmaa A, Lau NC, Li C, Velez J, Naik N (2007) Model projections of an imminent transition to a more arid climate in southwestern North America. Science 316(5828):1181-1184

Seth A, Rojas M, Rauscher SA (2010) CMIP3 projected changes in the annual cycle of the South American monsoon. Clim Change 98:331-357. doi:10.1007/s10584-009-9736-6

Sobel AH, Held IM, Bretherton CS (2002) The ENSO signal in tropical tropospheric temperature. J Climate 15(18):2702-2706

Sutton RT, Dong B, Gregory JM (2007) Land/sea warming ratio in response to climate change: IPCC AR4 model results and comparison with observations. Geophys Res Lett 34(L02701). doi:10.1029/2006GL028164

Tan PH, Chou C, Tu JY (2008) Mechanisms of global warming impacts on robustness of tropical precipitation asymmetry. J Climate 21:5585-5602

Tanaka HL, Ishizaki N, Nohara D (2005) Intercomparison of the intensities and trends of Hadley, Walker and monsoon circulations in the global warming projections. SOLA 1:77-80. doi:10.2151/sola.2005021

Taylor CM, Harris PP, Parker DJ (2010) Impact of soil moisture on the development of a Sahelian mesoscale convective system: a case-study from the AMMA special observing period. Q J R Meteorol Soc 136(S1):456-470. doi:10.1002/qj.465

Vecchi GA, Soden BJ (2007) Global warming and the weakening of the tropical circulation. J Climate 20:4316-4340

Vera C, Silvestri G, Liebmann B, Gonzalez P (2006) Climate change scenarios for seasonal precipitation in South America from IPCC-AR4 models. Geophys Res Let 33. doi:10.1029/2006GL025759

Wang B, Ding Q (2006) Changes in global monsoon precipitation over the past 56 years. Geophys Res Lett 33(6). doi:10.1029/2005GL025347

Webster PJ, Magaña VO, Palmer TN, Shukla J, Thomas RA, Yanai M, Yasunari T (1998) Monsoons: processes, predictability, and the prospects for prediction. J Geophys Res 103:14451-14510. doi:10.1029/97JC02719

Xie P, Arkin P (1996) Analysis of global monthly precipitation using gauge observation, satellite estimates and numerical model predictions. J Climate 9:840-858

Zhou T, Zhang L, Li H (2008) Changes in global land monsoon area and total rainfall accumulation over the last half century. Geophys Res Lett 35(16). doi:10.1029/2008GL034881 